\title{
Mathematical Model for Hereditary Transmission of Culture
}

\author{
Nita H. Shah \\ Department of Mathematics, \\ Gujarat University, \\ Ahmedabad, 380009 \\ Gujarat, India
}

\author{
Bijal M. Yeolekar \\ Department of Mathematics, \\ Gujarat University, \\ Ahmedabad, 380009 \\ Gujarat, India
}

\author{
Zalak A. Patel \\ Department of Mathematics, \\ L. D. College of Engineering, \\ Ahmedabad, 380015 \\ Gujarat, India
}

\begin{abstract}
Culture is the complex set of knowledge, beliefs, art, morals, customs and many more habits acquired by a human being a part of society or from hereditary. It defines the quality in a person. It is based on nurturing mind by education or training. In this paper, a mathematical model of a culture which gets transmitted directly from one generation to another also called vertical transmission as well as among the generation through concepts with society is formulated. Local and global stability is established and inheritance of the culture is discussed.
\end{abstract}

\section{Keywords}

Culture, Vertical and Horizontal Transmission, Local Stability, Global Stability

\section{INTRODUCTION}

Culture is the hereditary factor of the life of an individual, substance and spiritual in the society. The culture defined as the intellectual achievements in activities like folk dances, music, painting, instrumentation etc. The society is full of culture. The culture can be considered as a contagious disease that is inherited from the parents (called the vertical transmission) or from the contacts in the society (called horizontal transmission). Culture is a social heritage of a group of individuals in the society, for the society and from the society. It is different from age to age. In under aged class, the culture is only for entertainment while in adult class it is with social responsibilities and also had some criteria in mind that it is important or not, acceptable or not and right or wrong. Therefore, the culture transmission is different from one generation to another. To formulate the model, the total population is divided into two sub-populations, under aged and adult. The culture transmission is analogous to SIRS model. Both under-aged and adult sub-populations are divided further in three classes each, susceptible class, infected class and removed class. Thus total five compartments in this model viz. susceptible under-aged, active under-aged class, Susceptible adult, Infective adult, removed are considered. In susceptible under-aged class, individual is not yet actively interested in doing some activities. In active under-aged class, the person is active after exposure, after some time the underage individuals goes to susceptible adult class and continue this activity. If susceptible adults are highly interested or professionals then, they are continue their interest, and considered as infectious adult class. Removed class, in which a person has lost their interest or left the activity for some responsibilities but after some time, removed persons regain their interest and again joined susceptible adult class means passive member again become active after some time. The number of person in $\mathrm{S}$ class, I class and R class are denoted by Susceptible, infectious and removed class respectively.
In this paper, the mathematical model with hereditary transmission of SIRS model is formulated in section 2. The stability analysis of the transmission model derived in section 3 . In section 4 , model validated with numerical simulation and analysis. The hereditary transmission model ends with conclusion section.

\section{MATHEMATICAL MODELLING}

Anybody in the society is likely to acquired different types of culture from the society. In general, from one generation to another generation each individual are having different types of culture. Therefore, in formulating a model for culture, the population is divided in to five distinct compartments: Susceptible under-aged, Infective Under-aged, Susceptible adults, Infective adults and Removed. The susceptible individuals are those who exposed to intellectual activity. The infective individuals are those who are active towards an intellectual activity after exposure. The individuals who could not pursue for an intellectual activity due to academic or social responsibilities constitute a Removed class.

The rate of change of susceptible under-aged class is number of individuals who inherited from the parents and the rate at which under-aged individuals becomes active. The number of passive active contacts on proportion to the product of $S_{u a}$ and $I_{u a}$ of these contacts, $\beta_{1}$ fraction of individuals will develop active interest towards intellectual activity. Therefore, the rate of change in the susceptible under-aged population are given by

$$
\frac{d S_{u a}}{d t}=v_{t} S_{u a}-\beta_{1} S_{u a} I_{u a}
$$

The rate of which exposure takes place is called the incidence rate (Gross, 2004). Individuals of the susceptible under-aged class who become active moves to the infective under-aged class. The rate at which individual leave the susceptible under-aged class is equal to the rate at which they enter the infective class. Due to pressure of studies, number of individuals leave the infective under-aged class and join the removed class. If $\gamma_{1}$ denotes the fraction of individuals leaving the infective under-aged class, or getting susceptibleadult or infective-adult, then the rate of change of infective under-aged class is governed by the differential equation 


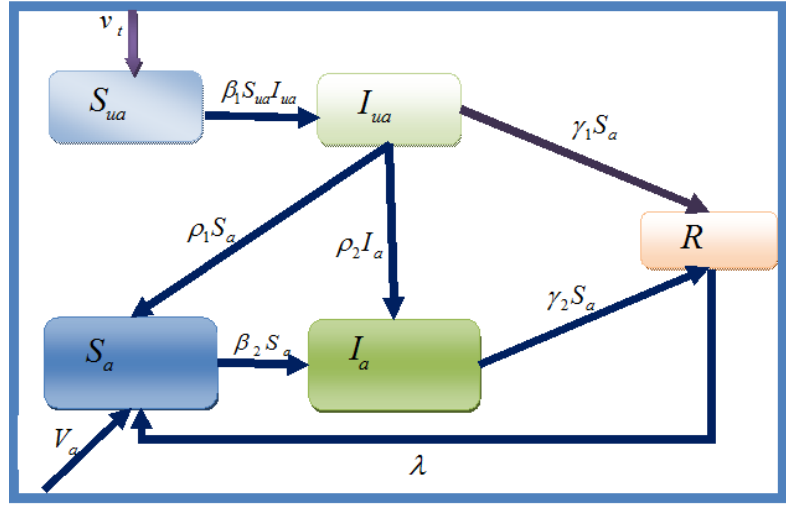

Fig 1: Culture Transmission diagram

$\frac{d I_{u a}}{d t}=\beta_{1} S_{u a} I_{u a}-\gamma_{1} I_{u a}-\rho_{1} I_{u a}-\rho_{2} I_{u a}$

The adult susceptible are those who acquired liking for intellectual activity through social contact at a rate $v_{a}$ or a fraction of active under-aged join due to social responsibilities. Also, the individuals who had left for some time may join susceptible adult class at the rate $\lambda R, 0<\lambda<1$. So, the rate of change of susceptible adult is given by

$\frac{d S_{a}}{d t}=v_{a} S_{a}+\rho_{t} I_{u a}-\beta_{2} S_{a}+\lambda R$

The susceptible adults becomes active in the intellectual activity with rate $\beta_{2} S_{a}$ and move to infective adult class which already has active infective under-aged, $\rho_{2} I_{u a}$ and due to sickness or change of place, infective individual move to removed class with rate $\gamma_{2}$. Then, the rate of change of infective adults is given by

$\frac{d I_{a}}{d t}=\beta_{2} S_{a}+\rho_{2} I_{u a}-\gamma_{2} I_{a}$

The individuals are in the removed class $R$ increases at a rate proportional to the number of active under-aged and active aged individuals entering the class. It decreases at a rate proportional to its size when an individual regains interest and joins the susceptible aged class. Therefore, the rate of change of individuals in the removed class governed by the differential equation

$\frac{d R}{d t}=\gamma_{1} I_{u a}+\gamma_{2} I_{a}-\lambda R$

Using equations (1) to (5), the dynamics of culture transmission in under-aged and adult individuals given by

$$
\begin{aligned}
& \frac{d S_{u a}}{d t}=v_{t} S_{u a}-\beta_{1} S_{u a} I_{u a} \\
& \frac{d I_{u a}}{d t}=\beta_{1} S_{u a} I_{u a}-\gamma_{1} I_{u a}-\rho_{1} I_{u a}-\rho_{2} I_{u a}
\end{aligned}
$$

$\frac{d S_{a}}{d t}=v_{a} S_{a}+\rho_{1} I_{u a}-\beta_{2} S_{a}+\lambda R$

$\frac{d I_{a}}{d t}=\beta_{2} S_{a}+\rho_{2} I_{\text {ua }}-\gamma_{2} I_{a}$

$\frac{d R}{d t}=\gamma_{1} I_{\text {иа }}+\gamma_{2} I_{a}-\lambda R$

Now, using the next generation matrix the basic reproduction number $R_{0}$ will found.

Let $X^{\prime}=\left(I_{u a}, S_{u a}, S_{a}, I_{a}, R,\right)^{\prime}$, where dash denotes derivative.

So that, $\quad X^{\prime}=\frac{d X}{d t}=\mathfrak{J}(X)-v(X)$

Where $\mathfrak{I}(X)$ denotes the rate of appearance of new individual in compartment and $v(X)$ represents the rate of transfer of culture, which is given as

$\mathfrak{I}(X)=\left[\begin{array}{c}\beta_{1} S_{\text {иа }} I_{\text {иа }} \\ 0 \\ 0 \\ 0 \\ 0\end{array}\right]$

and

$$
\begin{gathered}
v(X)=\left[\begin{array}{c}
\left(\rho_{1}+\rho_{2}+\gamma_{1}\right) I_{\text {иа }} \\
-v_{t} S_{\text {иа }}+\beta_{1} S_{\text {иа }} I_{\text {иа }} \\
-v_{a} S_{a}-\rho_{1} I_{\text {иа }}+\beta_{2} S_{a}-\lambda R \\
-\beta_{2} S_{a}-\rho_{2} I_{\text {иа }}+\gamma_{2} I_{a} \\
-\gamma_{1} I_{\text {иа }}-\gamma_{2} I_{a}+\lambda R
\end{array}\right] \\
D \mathfrak{I}\left(X_{0}\right)=\left[\begin{array}{ll}
F & 0 \\
0 & 0
\end{array}\right] \text { and } D v\left(X_{0}\right)=\left[\begin{array}{ll}
V & 0 \\
J_{1} & J_{2}
\end{array}\right]
\end{gathered}
$$

Where $F$ and $V$ are $5 \times 5$ matrices defined as

$$
F=\left[\frac{\partial \mathfrak{I}_{i}\left(X_{0}\right)}{\partial X_{j}}\right] \text { and } V=\left[\frac{\partial v_{i}\left(X_{0}\right)}{\partial X_{j}}\right] \text {. }
$$

Hence, 
$F=\left[\begin{array}{ccccc}\beta_{1} S_{\text {иа }} & \beta_{1} I_{\text {иа }} & 0 & 0 & 0 \\ 0 & 0 & 0 & 0 & 0 \\ 0 & 0 & 0 & 0 & 0 \\ 0 & 0 & 0 & 0 & 0 \\ 0 & 0 & 0 & 0 & 0\end{array}\right]$ and

$V=\left[\begin{array}{ccccc}\rho_{1}+\rho_{2}+\gamma_{1} & 0 & 0 & 0 & 0 \\ \beta_{1} S_{\text {ua }} & -v_{t}+\beta_{1} I_{\text {ua }} & 0 & 0 & 0 \\ -\rho_{1} & 0 & -v_{a}+\beta_{2} & 0 & -\lambda \\ -\rho_{2} & 0 & -\beta_{2} & \gamma_{2} & 0 \\ -\gamma_{1} & 0 & 0 & -\gamma_{2} & \lambda\end{array}\right]$

here, $V$ is non-singular matrix, so that the basic reproduction number $R_{0}$ is

$R_{0}=$ spectral radius of matrix $F V^{-1}$.

$$
\begin{aligned}
R_{0} & =\frac{\beta_{1} S_{u a}}{\left(\rho_{1}+\rho_{2}+\gamma_{1}\right)}-\frac{\beta_{1}^{2} S_{u a} I_{u a}}{\left(\rho_{1}+\rho_{2}+\gamma_{1}\right)\left[\beta_{1} I_{u a}-v_{t}\right]} \\
& =\frac{\beta_{1} S_{u a}}{\left(\rho_{1}+\rho_{2}+\gamma_{1}\right)}\left[\frac{v_{t}}{v_{t}-\beta_{1} I_{\text {uа }}}\right]
\end{aligned}
$$

Next, the equilibrium of the culture transmission system is discussed.

\section{EQUILIBIRIUM}

The cultural equilibrium is locally asymptotically stable if all the eigenvalues of the matrix have positive real values (AlAmoudi et al. (2014)).

\subsection{Stability of the equilibrium}

In this section, the local and global stability of the culture transmission model is discussed.

Now in the culture transmission model, for static change take all the rates are zero.

Therefore, $\frac{d S_{u a}}{d t}=0, \frac{d I_{u a}}{d t}=0, \frac{d S_{a}}{d t}=0, \frac{d R}{d t}=0$ and for $I_{a}$

$$
\begin{aligned}
S_{\text {иa }}{ }^{*} & =\frac{\rho_{1}+\rho_{2}+\gamma_{1}}{\beta_{1}} \\
I_{\text {ua }}{ }^{*} & =\frac{v_{t}}{\rho_{1}+\rho_{2}+\gamma_{1}} \\
S_{a}^{*} & =\frac{\lambda v_{a}\left(\rho_{1}+\rho_{2}+\gamma\right)+v_{t}\left(\lambda \rho_{1}+\gamma_{1}\right)+\gamma_{2} I_{a}\left(\rho_{1}+\rho_{2}+\gamma_{1}\right)}{\beta_{2}\left(\rho_{1}+\rho_{2}+\gamma_{1}\right)}
\end{aligned}
$$

$$
R^{*}=\frac{\gamma_{1} v_{t}+\gamma_{2} I_{a}\left(\rho_{1}+\rho_{2}+\gamma\right)}{\lambda\left(\rho_{1}+\rho_{2}+\gamma\right)}
$$

Putting (8) in (7), $R_{0}=\left[\frac{\left(\rho_{1}+\rho_{2}+\gamma_{1}\right)}{\left(\rho_{1}+\rho_{2}+\gamma_{1}\right)-\beta_{1}}\right]$
Which says that culture is transmitted only when $\rho_{1}+\rho_{2}+\gamma_{1}>\beta_{1}$ means if the interest under-aged individual continue their interest even though they have lots of academic responsibilities. i.e. if $R_{0}>1$ then culture gets transmitted.

\subsection{Sensitivity Analysis and Numerical \\ Simulation}

Let us validated our model using the following data

$$
\begin{aligned}
& \beta_{1}=0.03, \beta_{2}=0.01, \rho_{1}=0.04, \rho_{2}=0.05, \\
& \gamma_{1}=0.8, \gamma_{2}=0.9, \lambda=0.005
\end{aligned}
$$

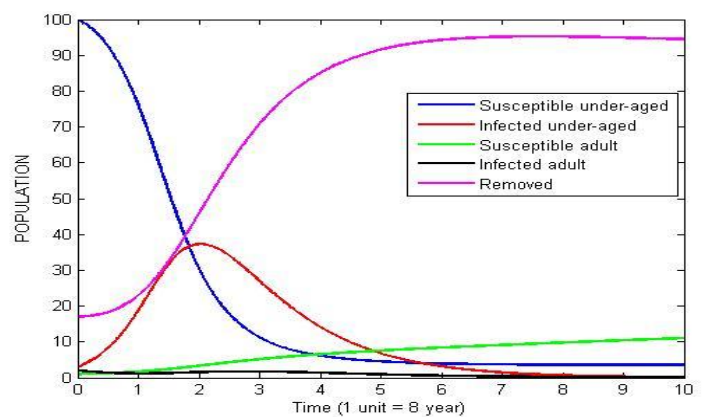

Fig 2: Transmission of culture transmissions model

From figure 2, it is observed that susceptible under-aged is moving towards culture adoption and hence there is an increase in active culture group up to 16 years. There after actively participated group losses, their interest in culture because of education and hence active culture group reduces and individuals move toward susceptible adult class. Infective under-aged moves towards active adult continue their interest as they are may be professionals and after 50 years of age get retired or losses interest and moves toward removed class with time span.

Using the above data, sensitivity of each is checked as follows:

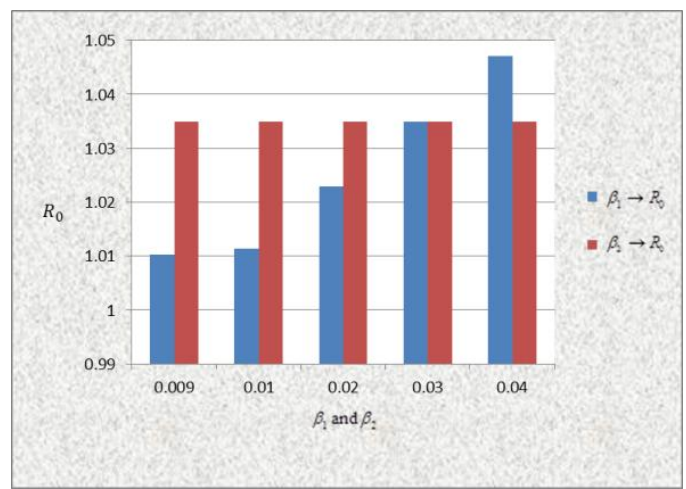

Fig 3: Effects of transmissions from susceptible to active classes

Figure 3 indicates that increase in transmission from susceptible under-aged to active under-aged increases culture spread, while susceptible adult to active adult keeps culture stable. 


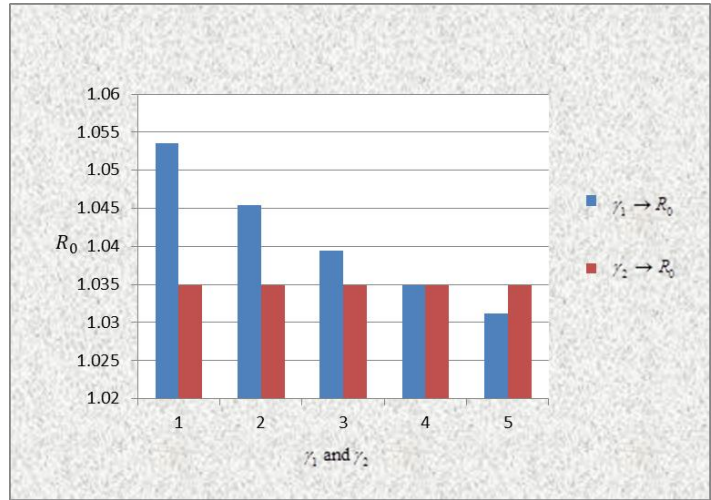

Fig 4: Effects of transmissions from active classes to removed class

From figure 4, it is observe that increase in transmission from active under-aged to removed i.e. loss of interest in culture reduces culture spread. In adult, loss of interest in culture does not harm culture stability.

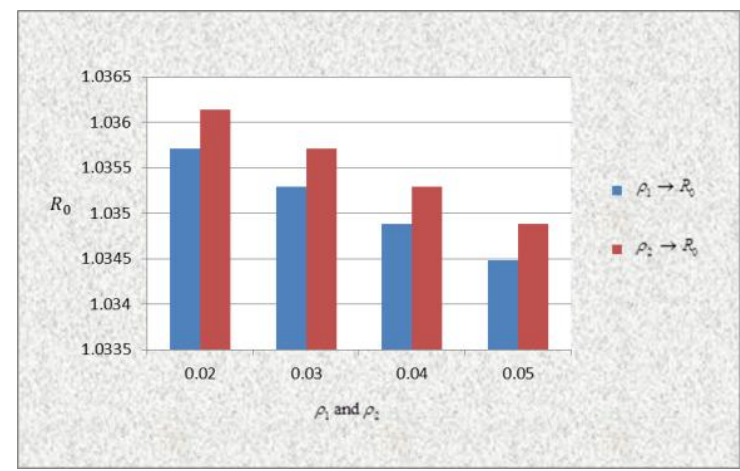

Fig 5: Effects of transmissions from active under aged to susceptible adult and active adult class
Figure 5 shows that increase in transmission from active under aged to susceptible adult and active adult class reduces culture spread. Susceptible adult have so many responsibilities so they are not actively participated in culture spread.

\section{CONCLUSION}

In this paper, the mathematical model to study the spread of the culture transmission in the society with social contacts and hereditary transmission is formulated. The stability of culture discussed with numerical data. The basic reproduction number is computed as 1.034, which shows that the culture activities are more in under-aged group. In adult group, it is lost because of academic and social responsibility. This suggested that the cultural activities and programme should be organized to increase more culture spread.

In future, one more treated class should be added, to consider those adults who get motivated to join again infected class from society.

\section{ACKNOWLEDGEMENT}

The authors thank reviewers for their constructive comments. The authors thank DST-FIST file I\# MSI-097 for technical support to the department.

\section{REFERENCES}

[1] Al-Amoudi, R., Al-Sheikh, S., and Al-Tuwairqi, S., (2014). Behavior of solutions to a mathematical model of memes transmission. International Journal of Applied Mathematical Research, 3 (1), 36 - 44.

[2] Johnson, L., (2004). An introduction to the mathematics of HIV/AIDS modelling. Centre for Actuarial Research.

[3] Malm J., (2004). A Mini-Essay on Epidemiological Modelling of Influenza. 